\title{
Transforming human nature in the digital age
}

\author{
Nikolay Rybakov ${ }^{1, *}$, Natalya Yarmolich $^{1}$, and Valery Romanov ${ }^{1}$ \\ ${ }^{1}$ Pskov State University, 2, Lenin Place, Pskov, 180000, Russia
}

\begin{abstract}
The article analyzes the problem of transformation of human nature in a modern digital society. The explication of the concept of "transformation" is given, the types of transformation are discussed, the connections between the concepts of "society" and "human being as a generic being" are revealed. The concepts of "human essence" and "human nature" are analyzed and compared, the uncertainty in the understanding of sociality is revealed, and the conclusion is made that the very concept of the essence of a person is largely amorphous. The complexity and multidimensionality of human nature is demonstrated, the relevance of its research is shown. This reveals the possibilities of the most diverse and, in the limit - inexhaustible - transformations of human nature. At the same time, the authors draw attention to the fact that the measure of possible transformations must be observed, since its violation inevitably turns into the disintegration of both man and society. The article notes that the most accessible and effective is the impact on the biological component of human nature. The connection between the transformation of human nature and modifications of the human worldview is stated. In this regard, the possibilities of transforming societies following the transformation of human nature are discussed. The authors come to the conclusion that as a result of ongoing transformations, a new type of society is emerging, which can be called a singular society, combining almost incompatible characteristics.
\end{abstract}

\section{Introduction}

The modern era is an era of total dynamism. Mobility, fluidity, honor, mobility - this is not a complete list of terms, with the help of which they describe the changes taking place in society. Along with them, another concept is widely used, which is total in nature and seems to be applicable to everything that happens not only in society, but also far beyond its borders. This is transformation. Researchers talk and write about the transformation of manufacturing, economics, health care, education, family, law, art, etc. But what is transformation?

A search engine in Yandex for this question gives a number of meanings of the term, but they all revolve around two basic meanings: transformation (Latin transformation) transformation, transformation (of one form into another) [1]. If you think about it, then in accordance with these meanings, firstly, we live in a world of continuous, total transformations, and secondly, the world itself is a mega, multitransformation, disintegrating

${ }^{*}$ Corresponding author: nik-rybakov@,yandex.ru 
into an infinite set of macro- and microtransformations - from the hypoworld to the hyperworld.

All this incredible variety of transformations must be conceptualized and ordered in some way. To conceptualize - because when analyzing world processes and events, well-known concepts immediately arise: change, movement, development, life, etc. Therefore, it is necessary to find a place among them for transformation. To arrange - because it is necessary to indicate the role of this concept in the construction of a picture of the world, be it a global or a local picture.

To describe the resulting picture, we introduce two categories: being and non-being, however, without further explanation, so as not to increase the volume of this article, and use the ideas of A. F. Losev [2]. They are interconnected through denial and the transition of one thing, for example, being into non-being, into another and back. When being and non-being in the limit rush towards each other, they become indistinguishable, identical. The coincidence of being and non-being is becoming. Mutual transition of one into another is transformation as transformation (transformation). This primary and most abstract transformation is change. It still has neither a definite form, nor, moreover, a definite content.

Becoming is continuous and continuous fluidity, its other is discontinuity and stability. This is how a new category arises, which is necessary for understanding the world - it has become a neck, frozen, and relatively stable. It has become possible to fix and designate: it is something in contrast to nothing. Something is a qualitative definiteness, a certain thing. The formation of a qualitative definiteness of a thing is its movement, which requires its carrier. Directed change turns out to be different for movement as the formation of that which at the very beginning of its formation contained the sources for its own deployment. Such a directional becoming (movement) is development as a rich becoming, suggesting the beginning and end of this process. In other words, development presupposes the correlation of what was at the beginning with what happened at the end of the change, which allows us to compare the features of the change in terms of differences in the internal structure of a thing, to fix its complication or simplification. Development is not just a directed change; it is associated with an internal transformation of the structure of a thing and is irreversible. The richest and most concrete, and therefore the most complex category, with the help of which the specifics of reality are revealed, is the category of life, which is based on the same category of becoming.

Going through these categories, we find that transformation as transformation, transformation (the transition of this into another) is immanently present in all designated categories - from becoming to life, as the most saturated category in which extraordinary dynamism is concentrated. It pulls them into a single knot as a kind of field of possibilities, as a kind of potential for all subsequent realizations. So, in conceptual terms, transformation should be qualified as a connection-translating category.

Already the ancient Greeks actively discussed the issue of the development of the world. At the same time, according to the cosmocentric worldview, the Cosmos moves cyclically: firstly, it is the basis and the beginning of everything that exists, and secondly, everything that has arisen, sooner or later, ends its existence in the very same space. It is no coincidence that the circle was the image of the ideal movement. In other words, movement in such a world is cyclical. What are its features?

Firstly, the cyclical nature is closed: the last element is replaced by the first, the process of replacement gives rise to the feeling of movement. And since the elements involved in such a movement are different, the cyclism is diversified. But sooner or later this diversity comes to an end due to the exhaustion of the cycle.

Secondly, no matter how much the length of the cycle increases and no matter how much its step is stretched, all the same, when it ends, the cycle transfers all the diversity into itself. 
And everything starts all over again. The cycle clearly presents the nature of movement as an eternal return to oneself: everything moves, but there is no development. There is a transformation within the cycle.

Thirdly, upon closer examination, it turns out that the cycle supports itself, not requiring any outside source. It is indestructible, reproducing itself through the replacement of the last element by the first.

Fourth, everything repeats in the cycle, therefore it does not need any special device to preserve the entire process. He has no memory, and it is not needed. And in the absence of memory, there is no need for history. History is a creation, the creation of something that did not exist before, but here there is simply a well-established and stable circle. Ecclesiastes is right: there is no memory of the past, and there will be no memory of what will happen either

Fifth, the substitution of elements that occurs within the cycle does not mean at all that the cycle itself as a whole is subject to change. Being indestructible, it remains the same, unchanged. It "stands" above both each of its elements and all the elements taken together. At the same time, as a whole, he is present in each of his elements, being an elusive demiurge. The cycle is an all-generating and at the same time all-absorbing, faceless and ruthless machine, which is the closest image of the super-reflective Cosmos, while being at the same time its visually tangible illustration.

All this reminds the processes taking place in the modern world, including Russia, in particular, the processes of reforming, in relation to which the concept of transformation is used. V. A. Yadov asserts: "The most general adequate concept, which is free from the" vector load "- the concept of transformation" [3]. True, for the analysis of social processes, the specific concept of "social transformation" is used, for which, however, as noted by V. V. Lokosov, "the absence of a distinct progressive, positive direction of changes" is characteristic [4].

So, in the process of constructing a picture of the world, the role of the category "transformation" as a category free "from vector load" becomes clear, i.e. talking about the changes taking place in the world, but not about their direction. This means that the category of transformation is ambivalent, it can talk about transformations from lower to higher (development, progress), from higher to lower (degradation, regression, destruction), and also express "running to nowhere" (marking time). In this respect, this category is very convenient for building any ideological constructions. In light of the above, the purpose of this study is to explicate the features of the transformation of the human world.

\section{Materials and methods}

So, transformation is a) transformation, b) transformation. These meanings have different meanings. The transformation, for example, of a caterpillar into a butterfly is a transformation that occurs due to internal reasons that do not depend on any external factors. This is the internal programming of the object, which must inevitably be realized. Transformation is a transformation that is largely carried out under the influence of some external factors in relation to the object. And although we call the transition of water from a liquid to a solid state, when the air temperature is less than zero under normal conditions, transformation, in fact it is a typical transformation. True, we can say that the transformation of water also occurs due to the peculiarities of the internal, atomic-molecular, structure of this object, but nevertheless there is no rigid internal programming here. The transformation of a caterpillar into a butterfly occurs regardless of external conditions - such is the organization of this object, while the transformation of water into a different state of aggregation does not 
inevitably happen due to the atomic-molecular structure of water, unless appropriate external conditions occur. It may happen that internal programming and external conditions are very closely related to each other. This happens in the so-called open systems, where the division into internal organization and external environment of the system becomes very relative. Then the transformation takes on a systemic character. The concept of "systemic transformation" is very intensively used in the process of analyzing the changes taking place in modern society.

A. V. Martynov notes: "A serious study of the problem of transformation of society, including in a purely concrete historical aspect, is called upon to rely on fundamental theory. However, a recognized theory of the transformation of social order has not yet been created". At the same time, he rightly emphasizes that the real picture of systemic transformation is expressed by "complex social interactions, simultaneously manifesting themselves in the roles of economic (market) agents, political players and actors in other arenas of social action ...", which should be taken into account the range of internal and external (external noneconomic, foreign policy and other driving forces of social change "and" the dependence in time and space of transformational shifts from institutional constraints that have developed in the past, always has a fundamentally important character" [5, p. 7, 52].

To complete the short portrait of the transformation, let's add a few more characteristics. $\mathrm{Yu}$. V. Yakovets believes that the category of transformation "in the generally accepted understanding means a change in the forms of life of public systems at different phases of their life cycle. This ... needs three comments.

Firstly, the transformation of the form is based on the transformation of the content of a particular social system, its structure and functions performed ... The external and internal conditions for the development of economic and social systems are changing - they are subject to change, more or less deep transformation of its content and its form.

Secondly, the very concept of transformation includes a certain volitional, conscious beginning. The transformation of social systems is carried out by people and is the result of their collective actions, although sometimes the result is largely unexpected for the participants in this process, although at the same time it is objectively conditioned by the laws of the development of society, its interaction with the dynamics of nature.

Thirdly, the depth and duration of the transformation are not the same for different economic and social systems and for different cycles of their dynamics. Some transformations are short-term and relatively easy and painless; others are more radical in nature and require serious changes in the structure, content and forms of economic and social relations; the third, the most profound, painful and long-lasting, can last for decades and even centuries and lead to the most significant changes in the structure of society when super-longterm, secular cycles change [6, p. 15-16].

Hence, we can conclude that the substrate of social transformations is the activity of people as the deep content of any social system, that an immanent feature of social transformation is its subjective component (conscious beginning) and that, finally, transformation cycles are quite diverse and have different depths of the transformations carried out. and the intensity of coverage of social structures (systems).

In this regard, we can talk about species transformations - economic, socio-cultural, political, etc., about global socio-systemic transformations covering society as a whole, which implies a transition to the generic concept of transformation as such. It is at this level that the need arises for the concept of transformation, so necessary for the development of the theory of social transformation, emerging into a more universal ideological context. From here, one can throw a bridge to the anthropogenic transformations that make up the main content of this study. The general scheme of this transition is as follows. 
Society - in an extremely abstract understanding - is the totality of social relations. In this case, the totality of social relations is what is called sociality. According to Marx, there are different types of sociality, giving historical types of societies. In other words, sociality is historically transformed under the influence of human activities. In the process of joint activities, people enter into social relations that express the essence of a person. Marx also wrote about this: the essence of man is the totality of social relations. Of course, here we are also talking about an extremely abstractly understood person, i.e., about a person as a generic being. Comparing two abstractions - society and man, we find that they boil down to the same thing - to the totality of social relations. In other words, society and man are one and the same. The same Marx called society "the inorganic human body." When we use the concepts of "society" and "man", we are talking about the same thing, only in different projections. Therefore, systemic social transformations are directly related to the transformations of a person, who is the subject and actor of the social process. Let us recall three attributes of social life - actors, resources, and institutions. Man is one of the dominant actors, man is one of the most important resources of social development, man is a part of social institutions. But when we talk about a person, the projection of the consideration of the entire social process changes. In this case, we should talk not only and not just about socio-systemic transformations, but about anthropogenic (anthropo-social) transformations.

The methods of system analysis, deductive inference and inductive generalization, analogy, comparative, logical and historical are used.

\section{Results}

The authors distinguish between the concepts of "human essence" and "human nature". Sometimes they are considered equivalent. But they have significant differences. Essence is the main thing that makes a person a person. The essence is formed under the influence of socio-anthropomorphic forces. As already mentioned, this is expressed in the well-known Marxist formula: the essence of a person is a set (ensemble) of social relations. The essence of a person is social and such will remain in any attempts to proclaim innovative discoveries in this area.

Many philosophers and sociologists wrote about sociality as the compatibility of human life. So, S. L. Frank, designated it with the concept of "we", which is something more than just the sum of many "I": "We" is ... a certain primary category of personal human, and therefore social being" [7]. P. Sorokin, speaking about an elementary generic model of a sociocultural phenomenon, writes: "The most generic model of any socio-cultural phenomenon is a significant interaction of two or more individuals" [8, p. 148]. M. Buber talks about the duality of the world and connects it with the duality of the main words spoken by a person. "One basic word is the I-Thou combination," which affirms the world of relationships and is primordial. "Another basic word is the I-It combination; moreover, without changing the main word, one of the words He and She can replace It" [9]. However, no matter what variations of sociality are encountered, virtually all researchers are unanimous that social life is the joint existence of individuals who are interconnected and are united into a unity. Individuals participate in this community, feel it. The question is this: if the connection between indie species is somehow felt, fixed, if its existence is stated, then what is its nature?

There have been many attempts to understand the nature of this connection, i.e., sociality. A rather widespread belief is that this connection is of a mental nature, depends on the will and consciousness of people. Many researchers considered this connection to be spiritual, while others saw its source in God, i.e., were inclined to talk about her religious origin. 
Marxism believed that this connection is material. An attempt to understand the nature of sociality on a non-productive basis was undertaken by K. Jaspers, using the concept of communication. He believed that communication is the primary reality that unites society into a whole. The fundamental theory of society based on communication in the XX century. developed by N. Luhmann, who believed that the social system is formed in general exclusively through communication.

The variations on the theme of sociality do not end there. The question of the nature of sociality is still open. And when the author of the actor-network theory B. Latour writes about the need to reassemble the social and notes that "there is nothing more difficult than to grasp social connections" [10], he is absolutely right, because sociality, while remaining to a certain extent sensory-tangible, because where does a person go from the feeling of "being in society," nevertheless remains invisible, devoid of color, smell, and physical parameters. Therefore, one can fully accept the exclamation of M. Thatcher quoted by him: "There is no such thing as society" [11].

The work of the group of authors edited by P. K. Grechko and E. M. Kumeleva is devoted to pluralistic sociality in the line of "ultimate questioning", in which the social is analyzed as meaningful being and various aspects of sociality are revealed. The authors rightly write: "If you try to find the most general, comprehensive or encompassing concept of social and humanitarian knowledge, then it will undoubtedly be "social", "sociality". All his storylines and connections are traced back to him. But since it is customary to differentiate and distinguish social and humanitarian knowledge, then, as a result, the "social" can be internally split into "social" and "human". More precisely, even so: the public and the human are two sides of a single reality studied by all social and human sciences. Before us is always a human (not necessarily human) society and a social person. Symmetry, or balance determination, however, is not here. Ultimately, the human itself is possible only in the bosom and on the basis of the social. No existential transcendences, as well as social ones: ideology, utopia, do not go beyond its borders either. The social lives by the constant transition of the human into the social and vice versa. This is a kind of human-social integrity" [12].

An interesting variant of understanding the social is presented in the work of V. M. Rozin "The nature of sociality. Problems of the methodology and ontology of social sciences", where the author identifies five tops (slices) of sociality, which, according to his plan, act as independent realities closely related to each other [13, p. 130-131].

Limiting ourselves to this very short list of different interpretations of the concept of "sociality", we can say that Marx's formula about the essence of man "as a set (ensemble) of social relations" is not so unambiguous. Its decoding depends on one or another explication of the concept of "sociality", up to extreme variants such as the fact that a person has no essence at all (D. Dennett). In other words, the question about the nature of sociality, therefore, about the essence of man remains open.

Let us now turn to the concept of "human nature". It expresses all that diverse content that forms completeness, and at the same time - the organicity and integrity of a person's being and "colors" his essence, giving it various shades up to the appearance and illusion.

Human nature is understood as immutable traits and characteristics inherent in humans regardless of biological evolution and historical process - this is a kind of complex of properties that are invariant with respect to various historical epochs, ethnic groups and cultures. D. I. Dubrovsky asserts: "The concept of human nature expresses a complex of stable properties of the social individual, which are reproduced in all epochs and among all peoples, which indicates that they are conditioned by our biological organization. These properties are formed on the basis of genetic factors and vary under the influence of external conditions - physical and social. They express the needs, drives, abilities, forms of behavior 
and human activity ... One can agree with the most common formulation that human nature is biosocial, while realizing, however, a clear account of its fundamental biological essence.

For the foreseeable period of history, human nature has not practically changed" [14].

The concept of "human essence" focuses the attention of the researcher on the social aspect of human being, while the concept of "human nature" covers all aspects of his existence. In this sense, the concept of nature is broader, more voluminous than the concept of the essence of man. Sometimes in the literature the concept of nature is expressed by the formula: man is a biopsychosocial-cultural being. These concepts are closely related. The deep connection between them lies in the fact that the biological component of human nature is not purely natural and, therefore, exclusively dominant. Human biology in the process of anthroposociogenesis is transformed under the influence of social factors, due to which the biological organization becomes exactly what it is and no other. In other words, human biology in the process of becoming a human being as a human being transformed from a purely animal into one, thanks to which a person acquired the ability to exist in society, to lead a social lifestyle. That is, biology itself became social. It cannot be ruled out that it was precisely the certain type of human biological arrangement in relation to the rest of living nature, which was formed in the process of anthroposociogenesis, that predetermined the appearance of sociality (as a social connection) that we have on our planet. The same can be said about the psyche, reason, culture and other components of human nature. Therefore, these concepts can neither be reduced to each other, nor separated from each other. Careless handling of them turns into an inevitable deformation, or even a complete distortion of ideas about both the essence of man and his nature.

On the Internet, you can find a discussion of the seven deadly sins from the point of view of the achievements of modern biological science. The first list of deadly sins was compiled by Gregory the Great back in the 6th century, and the concept of the seven deadly sins spread after the works of F. Aquinas in the 13th century.

Mortal sin is damage to the soul, which leads to its death, therefore, to damage to all human nature. Some modern genetics seek to provide them with an appropriate natural science base, trying to find in human nature the genes of pride, envy, gluttony, greed, fornication, etc. In this, however, there is still no crime. Problems begin after the responsibility for all of their sins is shifted onto the genes that are found in a person from birth. As a result, a person turns out to be innocent in himself - he is just a victim of his own genes, from which it is impossible to get rid of.

What a wonderful and effective "basis" for justifying the actions of any of him! And, let us note, with the help of the "discoveries" of genetics - the most rapidly developing science at present. After all, if everything in a person is determined by the presence of all sorts of genes, up to, excuse me, "the gene of constant picking in the nose", then, one wonders, what is then the meaning of the work of teachers, psychologists, the incredible efforts of educators to form the younger generation in the spirit of patriotism, honesty, hard work, initiative, etc.? Indeed, from their efforts, since a person is already born with a certain set of genes, nothing depends, and the profession of a teacher, educator becomes redundant, unnecessary. This, as predicted by the most advanced futurists, should happen by the middle of this century.

Therefore, the question of human nature is extremely relevant. However, one can hardly fully agree with the fact that human nature remains invariant and practically does not change. If the society in which a person lives changes, the types of sociality change, then after this, more precisely, at the same time, since this is actually one and the same process, the essence of a person changes, i.e., that is the core that makes a person a person. This, in one way or another, should lead to a change in human nature, to its modifications and transformations.

Marx, who discovered the types of sociality, noted that bourgeois society is characterized by relations of material dependence, where the thing (commodity) produced by them is the 
mediator in relations between people. They define the essence of a person. The measure of personality dignity in these conditions is the quantity and quality of the consumed goods. Consumerism is becoming the dominant feature in the life of the philistine, so vividly lived by the current generation of Russians.

In the information society, relations of information dependence are developing as a new type of sociality. Initially, parallel remains: in an industrial society, the measure of a person's dignity is the quality and quantity of goods consumed; in information, such a measure is the quantity and quality of information consumed. But there are also fundamental differences between them. A sensually tangible thing is replaced by an insubstantial substance that is entirely in the supersensible (semantic) sphere. Information has a material carrier and can be expressed with the help of signs, but it is immaterial. The symbolic component is brought to the fore, an era of intensive production of symbols that represent a new type of sociality begins.

In these conditions, the question of the possibility and necessity of transformation (transformation) of human nature becomes especially significant. The idea that human nature can be radically changed has previously been encountered in both religion and science. In Christianity, a view has arisen according to which, as a result of spiritual and moral practices, it is possible to create a "new man". In this regard, there was talk about the transformation of a person as about his ascent along the steps of perfection, for example, in the "Ladder" of John of the Ladder. Eugenics dreamed of breeding human breeds necessary for the existence of society, designed to perform certain functions.

The piquancy of the modern situation lies in the fact that if in previous epochs a person either did not encroach on what is accessible only to the Almighty, or tremblingly imagined that someday, in the distant future, he would be able to approach the mysterious act of creation, then in our days he no longer doubts his capabilities, without remembering about God the Creator. The act of the Divine creation of a person is now passing into the status of tech-ne - the ability to construct and practically reproduce a person as an ordinary utilitarian mechanism or an organism that, on occasion, needs technical and biological refinement. As a result, the concept of a posthuman arises, its three main forms are distinguished: cyborg, as a result of the fusion of a person with computer technology; a mutant to which the development of gene technology leads; clone as an exact genetic copy of the human body.

These are the main directions of global transformations of human nature. But there are still microtransformations that occur virtually continuously and imperceptibly, and the shifts seem insignificant. But in the end, they turn into radical transformations of human nature, as a result of which a return to the initial state is impossible.

As already mentioned, human nature includes many elements: a person is plural in his content. The Russian philosopher B. P. Vysheslavtsev revealed the content of human nature most impressively, highlighting seven ontological stages: man is a) physical and chemical energy; b) "living" energy, living cell; c) psychic energy, which in its hidden depth forms the collective-unconscious, as a common ground on which the individual soul grows and develops; d) the personal-unconscious, which rests on the foundation of the collectiveunconscious; e) co-knowledge, conscious soul; f) spirit, spiritual personality, and in this capacity he is the builder and bearer of culture; g) myself. "Selfhood is the last and highest seventh mystic step in the human being. For science, for rational thinking, it is unattainable and unprovable. The self is metaphysical and metapsychic. Only Revelation and mystical intuition indicate this ultimate depth. In practical life, in the knowledge of the world, even in the creation of culture, it can remain completely unnoticed" [15].

In the light of these views, a number of questions naturally arise.

First, can this plurality of elements be streamlined, brought into a system? 
Secondly, the answer to this question suggests that the idea of the unity, the wholeness of human nature should be the starting point for studying its various transformations.

Thirdly, only under the condition of the initial integrity of a person can we talk about the plurality of his nature, about the diverse real and potential modifications that happen to him.

Fourth, if the whole person is differentiated, are there limits to this? After all, at first, differentiation is an innocent and often just amusing, exotic hobby, but upon reaching its limit, the modifications of human nature become irreversible.

Fifth, does this mean that the modification and transformation of human nature is progress in its perfection, or is it its destruction, decay, behind which the end of human existence is visible?

What are the possible ways and means of transforming human nature? Based on the picture given by Vysheslavtsev, it can be argued that the directions and specific methods of transformation run along all these ontological steps - from the physicochemical composition of a person to his mystical self. Of course, it is inappropriate to describe in detail all possible ways in this publication, we will dwell in general terms on some points that take place in our life.

To do this, we will first use the idea of trimeria (trichotomy) of human nature: Christian anthropology proceeds from the fact that human nature is formed by spirit, soul and body. The question of the number of parts of human nature is at the same time the question of the completeness of its representation by a given number, as well as the question of the need for each part and their sufficiency together for a holistic representation of human nature. Whole person is such a person, all parts of the trimeria of which function together and harmoniously. Separate functioning violates harmony, an attempt to suppress each other by them and does lead to damage to human nature.

To maintain integrity, a person must constantly make significant efforts: there will always be factors that violate harmony. Spirit, soul and body, in turn, have a complex structure, and in order to maintain integrity, it is necessary that harmony also takes place inside each of these parts. Achievement by a person of the integrity and completeness of his nature is an extremely complex process that requires constant work on himself. In real life, all individuals have one or another damage to their nature, however, not everyone understands this circumstance.

Transformations of human nature are clearly revealed in the everyday life of people. Let's start with the human body. It is the most complex and multiple in its composition. We can say that the essence of the human body is at the same time the essence of human nature in general. In addition, in the object-material sense, it is more accessible for action in comparison with other elements. Once on the eve of the next New Year there was a wave of announcements: for the carnival night, you can make not only an excellent carnival costume, but also change the color of the eyes, or rather, irises, with the help of carnival lenses. You can choose the appropriate pattern of this shell, made in the shape of a heart or something else, you can choose other patterns, colors, etc. So far, this is being done only for a while, but the intensification of user demand is not far off.

Body transformations, from harmless bodybuilding, bodybuilding, plastic surgery, injections and beauty salons, which are designed to some extent to reduce the degree of concern and anxiety in people about their unsatisfactory and imperfect appearance, and ending with operations on gender reassignment - this is not a complete list of those manysided physical transformations, which are becoming massive in their scope and the consequences of which are difficult to calculate.

The soul is another major component of human nature, which has a multi-component structure. Small mind (spiritual), desire (epitimy) and feeling (thymos) are distinguished in it. Each of these elements is influenced in a certain direction: the small mind is transformed, 
for example, through the education system, which is now becoming one of the most noticeable factors of soul damage; desire - through the imposition of drives, through the imposition of the desire to become a millionaire, to make a career, to be successful; feeling through the incitement of passions, emotions and passions, and the trade in emotions and impressions is now becoming one of the most prosperous services and business, to some extent - the quintessence of digital society.

These transformations can be realized both independently of each other, both spontaneously and purposefully, consistently and systematically. How deep and bottomless the spiritual life is, can be judged by the works of the holy martyr Peter Damascene (XII century), who counted 298 different passions and 228 virtues [16]. So, the possibilities for transforming mental life are almost endless. In the presence of developed psychotechnics, transforming a person's mental life, or rather, distorting it, is not so difficult. This is what numerous psycho-trainings and training centers do, scattered all over the world and destroying the human psyche, and with it - the soul. It is possible that in the near future the world will learn about very unusual ways of soul transformation.

The third element of human trimerism - spirit - is associated with freedom, infinity, mobility, activity, higher intelligence, eternity, immortality. It is composed of mind (spiritual), will and strength. Will directs action, on the basis of it a person makes a decision to act or refuse to act. The execution of an action depends on the applied force; without it, neither the mind nor the will can manifest and be realized. The integrity of the spirit lies in the harmony of the joint action of its parts, without which the spirit is deformed and even disintegrated. The directions of transformation and mutation of the spirit are dictated by its composition: depriving the spirit of its intellectual principle (darkening of the mind), neutralizing the will in various ways, destroying the direction and concentration of forceful action. It is along the line of the spirit in modern society that the struggle for meanings and values is taking place, around this information confrontations and consecutive wars unfold.

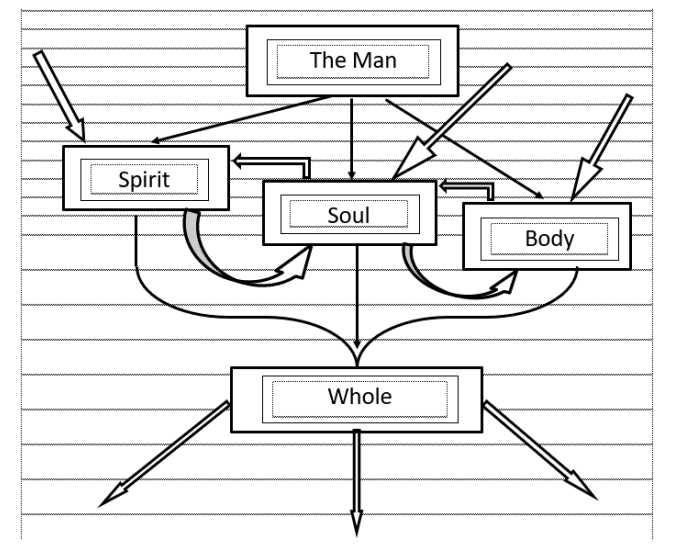

Fig. 1. The three-dimensional nature of the whole man' nature: spirit, soul, body. In today's environment, there are effects on every element of this nature, which leads to their deformations. As a result, the integrity of the trimeria is destroyed.

Human nature is trichotomous, including body, soul and spirit. Whole man is one, all parts of which act synergistically. Christian anthropology states that the center of trimeria is the human heart. Moreover, the heart, writes B. P. Vysheslavtsev, occupies a central place in the philosophy and religion of all peoples [17]. But so far, the main blow to this center has not been inflicted by modern technologies, while there is no talk of transforming the heart in this pragmatic-mystical sense. Although it is possible that technologies will reach him ... The 
violation of their joint activities turns into all kinds of damage to human nature, which may initially appear as harmless transformations.

In modern literature, the study of changes in human nature is carried out in connection with the implementation of the so-called NBICS technologies. I. V. Chernikova writes: "Human nature has become the most pressing problem of our time, requiring both scientific and philosophical analysis in connection with the possibilities of science and technology, especially the so-called NBIC technologies, to transform human genetics, his physicality, cognitive abilities, moral values" [18]

At the same time, the most noticeable shifts occur in the following parameters:

- bio- (corporality, environment, genetically modified products, etc.);

- info- (arrays of information falling on a person, which cannot be fully processed, nor, moreover, comprehended, which gives a person a feeling of uncertainty, incompleteness of existence, uncertainty, fear and is replenished by intensively produced illusions, speculations);

- cognitive (very noticeable transformations in this direction are associated with the sphere of education, which changes our thinking from whole-continuous to clip, mosaic);

- socio- (reformatting human behavior, especially in the current pandemic). New social formats are being formed, the essence of which is as follows: a person with a person must forget how to communicate live, people must start to be afraid of each other. All this is done in order to form an obedient person, a "service button person", an executor of someone else's will.

\section{Discussion}

As can be seen from the above, the possibilities for transforming human nature are extremely great. And humanity is still at the beginning of the path. Do not-simple questions arise about the prospects (future) of a person, his essence and nature? Why is it necessary to transform human nature? After all, it's one thing when it changes naturally in the process of evolution of human society, as if by itself. In this case, its drift and even occurring mutations are perceived rather calmly, as something inevitable and in the hope that everything will be straightened out, albeit not so soon. And it's another matter when a person begins to actively intervene in anthropo-social processes, for which various technologies are being developed, and transformation processes are significantly intensified. In this case, the consequences of such interventions become difficult to predict. Humanity is entering a period of uncertainty and risk.

The transformation of human nature can be carried out in two ways.

First, you can go from changing the essence of a person. Let us recall Marx's formula that the essence of man is the totality of social relations. A change in essence entails the transformation of all elements of human nature. The type of sociality is changing - the essence and nature of man are changing. But from the perspective of history, this path is extremely long and laborious. The fact is that the social essence of a person is clearly manifested only in a mature society, its mature stage, when the whole set of social relations has already taken shape, established itself and is acting. At the initial stage, social relations are still maturing, they are not sufficiently manifested, at the final stage they decompose, erode, become loose. In the transitional period, there are both rudiments and fragments of the departing, and the embryos of new social relations, here, too, there is no clear formulation, structure. Therefore, the question of the essence of man, even if we accept the Marxian formula, is not so simple and unambiguous. In addition, in the history of mankind, the replacement of some types of sociality with others often took place in the form of social revolutions that bring shocks to 
the entire public building. So, in order to change the essence and nature of man, it is not always advisable to start a revolution.

Secondly, you can go from changing the nature of man. Man as an individual constantly "looms" before his eyes, possessing a body and everything that is attached to it. Moreover, the body is the primary bastion that must be overcome (overcome), and the rest will already unwind by itself. Therefore, in attempts to transform human nature with the use of NBICS technologies, the emphasis is placed on the biological component. True, here the authors come into an implicit contradiction with their statements: they talk about the almost unchanging, invariant nature of man, based on a biological component; then it is this component that they first of all substitute for transformations. We emphasize once again that human nature is not an invariant, it is just as historical as society. But the impact on it creates additional opportunities for transformation of both the person and society. And this path seems to be more accessible technologically and even less sacrificial than the revolutionary one. But this does not make him more humane and moral.

Manipulation with the body (biological component) of a person cannot but affect the transformations of his soul and spirit. A. F. Losev asserted: "To pass from one spiritual stage to another, one must change physically" [19]. And if physical changes actually turn out to be mutations, then what kind of ascent to the degrees of spiritual perfection can we talk about?! He makes an amazing generalization, discerning the connection between the worldview and the composition of the blood, the state of the stomach, the life of the body as a whole: "I ... assert that you can change your worldview only by changing physically, bodily" [19]. A change in the mental and spiritual states of a person also affects his worldview.

So, in the conceptual aspect, the transformation of human nature has as its deepest result a change in a person's worldview. But the worldview of a person is classically formed under the influence of those basic intuitions (the primordial symbols of culture - A. F. Losev) that underlie a certain type of sociality; therefore, they are also responsible for the formation of the essence of a person. But going along the line of transformation of essence, as already mentioned, is long and laborious, because for this it is necessary, at least, to change the social system, and this is an evolutionary process. But a person has the opportunity to intervene in this process technologically - through the elements of his own nature, which is much more accessible. They changed the body, modified the soul - so the transformation of human nature began, followed by shifts in the worldview. As a result, the question arises of replacing the old basic intuition with a new one, so it comes to transforming the foundations of existing sociality. Even if this chain is also not so unambiguous, it is visible and therefore can be used. First at the level of the individual, then at the level of man as a generic being. It is in this style that the governments of many countries in the fight against the COVID-19 pandemic hope to build herd immunity!

By transforming human nature, we are changing our worldview. So, we take a step towards changing our essence and re-commute the society in which we live. Therefore, it is far from harmless what and how we do, what and how we legalize in these actions. It is necessary to build in a person a system of his own internal protection, which protects him from deformation and disintegration of his own integrity. This means, from accidental and, moreover, conscious and purposeful transformations leading to irreversible damage to its nature. This is a question about the safety of both human life and society.

In the modern era, a certain type of sociality is taking shape - the relationship of information dependence. More precisely, the relationship of information-personalized dependence, since information has the property not only to function in the information space, for example, on the Internet, but to enter the individual's consciousness exactly in the way he searches for it, perceives it, filters, etc. The Internet is one of the most voluminous and unexpected mussitations that humanity has plunged into. It is strange and alarming to see 
individuals climb in there, spread outright nonsense about their own - especially narrow problems - down to the smallest pimples. And it is even more ridiculous to determine the significance of the material posted there by the number of views (likes). In addition, few people worry that any idea, including a brilliant one, can be defiled, turned inside out. One gets the impression that the Internet is the personal inner world (s) of individuals, turned outward. What was previously hidden, guarded, trusted in a personal diary, is now put-on display for all to see. But this world remains a representative of its own wretched world. Outside and inside are changing poles, borders are collapsing, but because what awaits us in this massiveization, multiplied by the imposed digitalization, only God knows. But this name already exists - degradation, degeneration ...

The Internet fragments, breaks the social ties of individuals, forcing them to capitalize in their own world. But it is still impossible to break away from the umbilical cord of sociality - it just manifests itself in laying out the content of one's intimate world outside, exposing it to a universal review. COVID technologies enhance the effect of the destruction of sociality, and it is quite legitimate throughout the world that a social security remote station of $1.5 \mathrm{~m}$ is introduced, which, as it were, sets the dimensions of the cell, which forms the basis of the sociality formatted as a result of the fight against the pandemic. We become witnesses and accomplices in the formation of two mutually exclusive tendencies: on the one hand, personified information, reinforced by quarantine anti-pandemic measures, closes the individual in his isolated niche (social capsule); on the other hand, thanks to information technologies that have been multiplied by digitalization, this isolation is overcome, more precisely, quasi-overcome, because connections between individuals move to the virtual level, so that a new sociality is formed, or rather, quasi-sociality.

As a result, a kind of singular society develops, i.e., incredible and impossible phenomenon. If society is individuals and the connection between them, expressed in the form of exchange (activity and its products), then the new formation is a kind of antipode: individuals are encapsulated, each is on its own, without communication and direct exchange of activity and its products with each other, but at the same time - the presence of quasiexchange through the exposure of the inner world in the information space to the general public. Sociality in a singular society "seeps" from individual to individual through some analogs of quantum barriers, which have not yet been explicitly discovered, but already have the general name of digitalization. But this means that despite and despite the predictions about decentration, the disintegration of human nature, entailing the erosion of his identity and sociality, both man and society will continue to exist. This will be a completely new and unusual type of sociality, a new human nature, about the contours of which we will refrain for now.

\section{Conclusions}

The transformation of human nature is possible in various directions and carries inexhaustible options. These options become many times stronger and more complicated when we take into account the developing NBICS technologies and the intensively going digitalization processes of modern society. Ultimately, changes in human nature lead to changes in the world outlook of a person and society, and through this they influence the transformation of the society itself, the dominant type of sociality. Therefore, a person bears enormous responsibility for active actions in this area and must control every step so that the results obtained do not get out of control and turn into a total destructive force. 


\section{References}

1. A.N. Chudinov, Transformation, URL: https://dic.academic.ru/dic.nsf/dic fwords/36473/TRANSFORMACIYa

2. A.F. Losev, The most, URL: http://psylib.org.ua/books/losew04/

3. V.A. Yadov, Russia as a transforming society: a summary of the long-standing discussion of sociologists, URL: http://ecsocman.hse.ru/data/009/681/1219/048Yadov.pdf

4. V.V. Lokosov, Social transformation, URL: http://ponjatija.ru/node/16103

5. A.V. Martynov, Transformation of macro-social systems in the post-socialist world: methodological aspect, URL: http://window.edu.ru/resource/894/37894/files/martynov.pdf

6. Yu.V. Yakovets, Global Economic Transformations of the 21st Century, URL: https://economy-ru.com/mirovaya-ekonomika-uchebnik/ponyatie-vidyi-transformatsiy$\underline{35638 . h t m l}$

7. S.L. Frank, Spiritual Foundations of Society. Introduction to social philosophy, URL: https://azbyka.ru/otechnik/Semen Frank/duhovnye-osnovy-obshestva/1 15

8. P. Sorokin, Structural Sociology, URL: www.sociology.kpi.ua/wp-content/uploads/2019/02/sorokin.pdf

9. M. Buber, Me and You, URL: http://psylib.org.ua/books/buber01/index.htm

10. B. Latour, Reassembling The Social. An Introduction to Actor-Network-Theory, URL: https://mir-knig.com/read 241327-54\#

11. B. Latour, Reassembling The Social. An Introduction to Actor-Network-Theory, URL: https://mir-knig.com/read 241327-2\#

12.P.K. Grechko, Social: origins, structural profiles, modern challenges, URL: https://texts.news/sotsialnaya-filosofiya-besplatno/chast-kontseptualno-metodologicheskie-srezyi.html

13. V.M. Rosin, Nature of Sociality. Problems of methodology and ontology of social sciences (M.: LENAND, 2016)

14. D. Dubrovsky, Human Nature, Collective Consciousness, and Global Future. Russian Journal of Philosophical Sciences (9), 5-14 (2013)

15. B.P. Visheslavtsev, What am I? URL: https://azbyka.ru/otechnik/Boris Vysheslavcev/chto-takoe-ja-sam/

16. The creations of the Reverend and God-bearing Father of our Holy Martyr Peter Damascusin, URL: https://www.xpa-spb.ru/libr/_Petr-Damaskin/tvoreniya-all.html\# 210

17. B.P. Visheslavtsev, Eternal in Russian philosophy. Section H. The Value of the Heart in Philosophy and Religion, URL: https://azbyka.ru/otechnik/Boris_Vysheslavcev/vechnoe-v-russkoj-filosofii/10

18. I.V. Chernikova, V.V. Sherenkova, The problem of human nature conservation as a new aspect of the identity crisis, Bulletin of Tomsk State University 399, 24-27 (2015) DOI: $10.17223 / 15617793 / 399 / 5$

19. A.F. Losev, History of Aesthetic Teachings (VIII), URL: https://litresp.ru/chitat/ru/L/losev-aleksej-fedorovich/forma---stilj---virazhenie/3 